\title{
Konseling Kelompok Teknik Cognitive Restructuring Bermuatan Nilai Budaya Minangkabau
}

\author{
Siska Putri Ayu ${ }^{1}$, Carolina L. Radjah ${ }^{1}$, Nur Hidayah ${ }^{1}$ \\ ${ }^{1}$ Bimbingan dan Konseling-Universitas Negeri Malang
}

\section{INFO ARTIKEL}

\section{Riwayat Artikel:}

Diterima: 11-10-2019

Disetujui: 11-05-2020

Kata kunci:
technique counseling guides;
cognitive restructuring;
verbal bullying;
panduan teknik konseling;
cognitive restructuring;
perundungan verbal

\section{Alamat Korespondensi:}

Siska Putri Ayu

Bimbingan dan Konseling

Universitas Negeri Malang

Jalan Semarang 5 Malang

E-mail: siska2pu3@gmail.com

Berkembangnya potensi siswa dengan maksimal merupakan tujuan pendidikan nasional, dan tentunya juga menjadi tujuan penyelenggaraan bimbingan dan konseling di sekolah (UU No. 20 Tahun 2003; Kemendikbud, 2016). Dengan harapan, siswa menjadi manusia yang beriman, bertakwa, berakhak mulia, sehat, berilmu, cakap, kreatif, mandiri, menjadi warga negara yang demokratis, dan bertanggung jawab. Penyelenggaraan pendidikan di sekolah tidak lepas dari berbagai masalah yang dapat menghambat berkembangnya potensi siswa dengan baik. Diantara permasalahan yang sering terjadi pada siswa di sekolah adalah fenomena bullying atau disebut juga dengan perundungan. Perundungan atau dikenal dengan istilah bullying merupakan tindakan agresif yang sengaja dilakukan oleh seseorang atau sekelompok orang yang lebih kuat terhadap orang lain yang lebih lemah secara berulang kali (Olweus, 1993). Rigby (2004) menambahkan bahwa perilaku agresif dikategorikan sebagai perundungan ketika pelaku mempunyai niat dan maksud untuk menyakiti korban sehingga korban menderita secara fisik maupun psikis.

Hasil studi pendahuluan di SMP Negeri 2 Situjuah Limo Nagari menunjukkan bahwa perundungan yang sering terjadi dan sulit diatasi adalah perundungan verbal. Perundungan verbal adalah perundungan yang berbentuk ucapan atau ujaran, bersifat langsung dan tidak langsung. Perundungan verbal langsung berupa name calling, ejekan, hinaan dan sebagainya. Perundungan verbal tidak langsung berupa penyebaran rumor, baik fitnahan maupun aib atau sesuatu yang memalukan. Hal ini sejalan dengan hasil penelitian oleh (Tumon, 2014) terhadap 188 siswa berusia 12—17 tahun pada tiga SMP di Surabaya Timur yang menunjukkan bahwa bentuk perundungan yang sering dilakukan siswa adalah perundungan verbal.

Perundungan verbal sama halnya dengan perundungan fisik juga mendatangkan dampak negatif dan serius. Hasil penelitian oleh (Ayu Suciartini \& Unix Sumartini, 2019) menunjukkan bahwa dampak negatif yang dialami korban perundungan verbal adalah kehilangan kepercayan diri, disfungsi sosial, percobaan bunuh diri, dan menjadi pelaku perundungan. Ini sejalan dengan hasil penelitian Tumon yang menunjukkan bahwa korban perundungan verbal beresiko mengalami depresi ang memunculkan keinginan untuk bunuh diri atau melukai diri sendiri. Dampak negatif ini tentunya dapat menghambat siswa dalam mencapai perkembangan diri yang optimal. Oleh sebab itu, upaya yang perlu dilakukan tidak hanya untuk membantu korban, namun juga menghentikan atau mengurangi tindakan perundungan yang dilakukan oleh siswa sebagai pelaku. Penghentian atau pengurangan perilaku perundungan juga perlu dilakukan dalam upaya membantu pelaku agar terbebas dari 
perilaku maladaptif atau berbagai konsekuensi akibat perundungan yang dilakukannya. Sucipto (2012) menyatakan bahwa pelaku perundungan berisiko menjadi pelaku tindak kriminal di kemudian hari. Salah satu strategi yang dapat dilakukan guru BK untuk mengurangi perundungan verbal siswa adalah dengan menciptakan perubahan pikiran yang melandasi perilaku tersebut melalui konseling kognitif perilaku.

Model konseling kognitif perilaku menekankan pentingnya proses kognitif terhadap munculnya tingkah laku. Model ini berasumsi bahwa bagaimana seseorang merasa dan bagaimana tingkah laku yang dimunculkan sangat dipengaruhi oleh penilaian dan interpretasi subjektifnya terhadap situasi, kemudian interpretasinya tersebut dipengaruhi oleh keyakinan, asumsi dan proses kognitifnya (Corey, 2013). (Alabi \& Lami, 2015) menyebutkan bahwa pelaku perundungan memiliki interpretasi realitas yang tidak rasional. Interpretasi ini diantaranya menuntut sesuatu yang tidak realistis dari orang lain, membesarbesarkan sesuatu yang tidak disukai serta menyimpulkan bahwa orang lain tidak dapat mentolerir hal yang tidak disukainya, menyalahkan atau mengutuk dunia, orang lain dan diri sendiri. Senada dengan itu (Olatunbosun, 2016) menyatakan bahwa pelaku perundungan memiliki pola pemikiran yang salah atau terdistrosi, seperti semua orang membenci saya, saya perlu menggunakan kekuatan untuk mendapatkan apa yang saya inginkan atau saya tidak pernah mendapatkannya, hidup adalah pertarungan. Pikiran yang terdistrosi ini muncul pada pelaku perundungan dalam kehidupan sehari-hari sehingga berkontribusi pada timbulnya kecemasan, kemarahan, kemudian mendorongnya melakukan tindakan agresif dan perundungan atau masalah psikologis dan perilaku lainnya. Hal ini juga diperkuat oleh penelitian (Narimani \& Samadifard, 2017) yang menunjukkan bahwa kepercayaan irasional, efikasi diri, dan mindfulness memiliki hubungan yang signifikan dengan perilaku perundungan seseorang.

Salah satu teknik dalam konseling kognitif perilaku yang dapat digunakan untuk mengubah pikiran negatif atau irasional pelaku perundungan adalah teknik cognitive restructuring (CR). Melalui teknik ini dibangun kesadaran konseli bahwa terdapat hubungan antara perilaku dengan pikiran dan perasaan, konseli juga dibantu untuk bisa membedakan pikiran negatif atau irasional dengan pikiran positif atau rasional. Setelah itu konseli melakukan identifikasi pikiran negatif yang melandasi perilaku maladaptifnya, kemudian mengubahnya menjadi lebih positif. Perubahan pikiran menjadi positif atau rasional akan berpengaruh pada perubahan perilaku yang lebih adaptif. Teknik ini didasarkan atas pandangan bahwa respons perilaku dan emosional individu dipengaruhi oleh keyakinan, sikap dan persepsinya (Cormier, Nurius, \& Osborn, 2009). Teknik CR telah digunakan oleh beberapa peneliti sebelumnya untuk menciptakan perubahan perilaku, diantaranya (Steigerwald \& Stone, 1999) yang menggunakan teknik CR untuk mengobati para pecandu alkohol. Ekennia, et al. (2013) menggunakan teknik CR untuk mengelola kebiasaan ngompol malam hari di kalangan remaja SMP dan (Chrétien, Giroux, Goulet, Jacques, \& Bouchard, 2017) meneliti teknik CR untuk membantu klien yang kecanduan judi.

Siswa SMPN 2 Situjuah Limo Nagari merupakan masyarakat Minangkabau yang sebetulnya memiliki nilai-nilai budaya sebagai pedoman kehidupan pribadi dan sosial. Nilai-nilai budaya yang ada di tengah masyarakat ini mempunyai peran yang sangat penting dalam membentuk kehidupan masyarakat yang harmonis. Namun nilai ini mulai tergeser seiring dengan pesatnya perkembangan teknologi informasi. Oleh sebab itu, pemuatan nilai budaya ke dalam proses konseling dapat menjadi salah satu laternatif strategi dalam menciptakan perubahan perilaku siswa menjadi lebih baik, dalam hal ini berkurangnya perilaku perundungan verbal. Sebagaimana (Hidayah \& Ramli, 2017) bahwa Indonesia perlu mengkaji variabel budaya dalam proses konseling mengingat bangsa Indonesia merupakan bangsa yang kaya akan budaya. Pengadopsian nilai-nilai budaya ke dalam proses konseling dapat mendukung pelaksanaan konseling yang efektif.

Minangkabau memiliki nilai-nilai kehidupan yang positif. Falsafah hidup masyarakat Minangkabau adalah Adat Basandi Syarak, Syarak Basandi Kitabullah (Adat Berlandasrkan Syariat, Syraiat Berlandaskan Kepada Kitab Allah/ABSSBK) dan berguru kepada alam atau dikenal dengan istilah Alam Takambang Jadi Guru (Alam Semesta Dijadikan Guru) artinya segala sesuatu yang terjadi di alam semesta, baik gejala alam maupun yang terjadi pada manusia merupakan pelajaran dalam kehidupan. Nilai-nilai dan ajaran positif Minangkabau ini tertuang dalam bentuk pepatah petitih. Terdapat banyak pepatah petitih yang telah dirangkum oleh berbagai penulis ahli budaya Minangkabau, dintaranya berhubungan dengan perundungan verbal yaitu nilai urang sabana urang, nilai sumbang kato, nilai raso jo pareso, nilai sopan santun dan nilai saiyo jo sakato. Sementara itu, pepatah petitih yang berhubungan dengan proses cognitive restructuring mencakup nilai urang sabana urang, nilai sumbang kato, nilai isi jo batin saukuran, nilai raso jo pareso, nilai iduik baraka baukua jo bajangko, nilai sopan santun, nilai lanca kaji dek baulang pasa jalan dek batampuah dan nilai alun takilek alah tatarang (Munir, 2013); Attubani, 2014). Panduan teknik CR bermuatan pepatah petitih Minangkabau yang teruji kelayakannya melalui uji ahli dan calon pengguna dapat membantu guru BK sebagai alternatif strategi untuk mereduksi perilaku perundungan verbal siswa.

\section{METODE}

Penelitian dan pengembangan ini menggunakan model Borg \& Gall (1983) yang tahapannya dimodifikasi dan disesuaikan dengan kebutuhan penelitian. Prosedur untuk memperoleh validasi panduan teknik CR yang dikembangkan dilakukan melalui tiga tahap, yaitu (1) tahap pra pengembangan, yaitu kegiatan mengumpulkan data dan informasi mengenai kebutuhan konselor dan studi literatur; (2) tahap pengembangan, yaitu pengembangan prototype awal berupa rumusan rasional pengembangan, tujuan, sasaran pengguna, konsep teknik cognitive restructuring dalam kegiatan konseling kelompok kognitif perilaku, tahapan konseling serta rincian kegiatan konseling kelompok; (3) tahap pasca pengembangan atau tahap validasi, 
tahap ini merupakan kegiatan penilaian oleh empat orang ahli dan dua orang calon pengguna untuk memperoleh validasi dan kelayakan panduan. Instrumen validasi adalah skala penilaian yang disajikan pada tabel 1.

Tabel 1. Interpetasi Skala Penilaian Ahli

\begin{tabular}{cl}
\hline Skala & \multicolumn{1}{c}{ Indikator } \\
\hline 1 & Sangat Tidak Tepat / Sangat Tidak Jelas / Sangat Tidak Berguna / Sangat Tidak Menarik \\
2 & Tidak Tepat / Tidak Jelas / Tidak Berguna / Tidak Menarik \\
3 & Tepat / Jelas / Berguna / Menarik \\
4 & Sangat Tepat / Sangat Jelas / Sangat Berguna / Sangat Menarik \\
\hline
\end{tabular}

Analisis data angka dilakukan dengan kesepakatan rater yang diusulkan Aiken dalam Azwar (2012) dengan rumus:

$$
V=\sum S /[n(C-1)]
$$

Keterangan

$$
\begin{aligned}
& \mathrm{V}=\text { Skor empirik validator } \\
& \mathrm{S}=\mathrm{r}-\mathrm{lo} \\
& \mathrm{LO}=\text { angka penilaian terendah } \\
& \mathrm{C}=\text { angka penilaian tertinggi } \\
& \mathrm{R}=\text { angka yang diberikan oleh penilai }
\end{aligned}
$$

Hasil analisi ditafsirkan dengan mengacu kepada tabel kriteria penilai ahli oleh (Hsu, Lin, Chang, Tseng, \& Chiu, 2015) yang disajikan pada tabel 2.

Tabel 2. Tabel Kriteria Koefesien Validasi

\begin{tabular}{cc}
\hline Indeks Kesepakatan & Kategori Validitas \\
\hline $0,71-1,00$ & Tinggi \\
$0,31-0,70$ & Sedang \\
$0,00-0,30$ & Rendah \\
\hline
\end{tabular}

Data yang diperoleh dari hasil uji ahli, tidak hanya berupa angka, namun juga non angka. Data non angka diperoleh dari saran dan masukan dari para ahli. Data non angka dijadikan sebagai acuan dalam melakukan revisi atau perbaikan panduan.

\section{HASIL}

Setelah melalui serangkaian tahapan penelitian dan pengembangan, dihasilkan produk berupa buku panduan yang layak digunakan oleh guru BK. Secara ringkas, prosedur tahapan teknik CR bermuatan pepatah petitih disajikan pada tabel 3 . Adapun hasil analisis data angka yang diperoleh dari penilaian para ahli dan calon pengguna disajikan pada tabel 4 .

Berdasarkan tabel 3 dapat diketahui bahwa hasil penilaian media pembelajaran memberikan angka indeks validasi sebesar 0,92. Artinya, hasil penilaian ahli media pembelajaran menunjukkan bahwa panduan teknik cognitive restructuring bermuatan nilai budaya Minangkabau untuk mereduksi perilaku perundungan siswa SMP valid untuk digunakan dan merupakan media pembelajaran yang layak untuk digunakan. Data non angka dari ahli media berupa saran dan masukan yang diperoleh adalah (1) warna sampul diperbaiki dan disesuaikan dengan kebutuhan calon pengguna, (2) tata letak nama penulis diubah, (3) penggunaan kotak pada verbatim diubah dengan warna latar, (4) sertakan catatan kaki dan judul punggung sampul.

Data non angka pertama menunjukkan bahwa warna yang dipilih sebagai latar sampul panduan tidak salah namun perlu disesuaikan dengan kebutuhan calon pengguna. Masukan ahli ini disikapi dengan mengubah warna latar sampul dengan warna khas Minangkabau karena calon pengguna adalah guru BK Minangkabau, kemudian dilakukan pertimbangan lebih lanjut dengan hasil kebutuhan lapangan. Data non angka kedua menunjukkan perlu perbaikan pada tata letak nama penulis di sampul panduan, hal ini bertujuan agar tercipta fokus pandang yang baik. Data non angka ketiga menunjukkan perlu perubahan pada penggunaan gambar kotak dengan warna latar untuk menghindari kebosanan pembaca. Data non angka keempat menunjukkan perlu adanya penambahan catatan kaki pada halaman isi dan judul punggung pada sampul, penambahan keduanya bertujuan untuk mempermudah pembaca dalam menggunakan dan menemukan buku.

Hasil penilaian ahli konseling memberikan angka indeks validasi sebesar 0,81. Angka ini termasuk pada kategori validasi yang tinggi. Maka dapat dimaknai bahwa panduan teknik cognitive restructuring bermuatan pepatah petitih untuk mereduksi perilaku perundungan verbal siswa merupakan panduan teknik konseling yang layak digunakan oleh guru bimbingan dan konseling. Data non angka yang diperoleh dari masukan dan saran ahli konseling adalah (1) spesifikasi tujuan yang akan dicapai tiap pertemuan konseling, (2) pembagian tahapan CR pada setiap pertemuan diganti dan disesuaikan, dan (3) instrumen pengukur perundungan verbal diganti dengan inventori. 
Data non angka pertama dari ahli konseling menunjukkan bahwa tujuan yang akan dicapai oleh siswa pada setiap pertemuan dispesifikkan, agar konselor dan siswa memahami apa yang harus dicapai tiap pertemuan. Data non angka kedua menunjukkan bahwa seluruh tahapan teknik CR terlalu kompleks jika dilakukan di setiap pertemuan konseling. Oleh sebab itu, tahapan teknik CR dibagi di setiap pertemuan agar efektif dalam mencapai tujuan yang diinginkan. Data non angka ketiga dari ahli konseling menunjukkan perlu adanya perbaikan pada jenis instrumen yang digunakan sehingga terdapat keselarasan antara alat ukur dengan yang perlu diukur.

\section{Tabel 3. Prosedur Tahapan Teknik Cognitive Restructuring Bermuatan Pepatah Petitih Minangkabau}

\begin{tabular}{|c|c|c|}
\hline Tahap Teknik Cognitive Restructuring & Nilai Pepatah Petitih & Deskripsi \\
\hline 1. Rasional pelaksanaan teknik & $\begin{array}{l}\text { Urang nan sabana urang } \\
\text { (manusia yang sesungguhnya } \\
\text { dalam pandangan adat } \\
\text { Minangkabau). } \\
\text { Sumbang kato (cara berbicara } \\
\text { mesti sesuai dengan kepatutan } \\
\text { dan kepansan). } \\
\text { Lahia jo batin saukuran, isi } \\
\text { kulik saumpamo lahia } \\
\text { (perbuatan atau tindak tanduk } \\
\text { menggambarkan pikiran dan } \\
\text { perasaan). }\end{array}$ & $\begin{array}{l}\text { Siswa diberi arahan dan pemahaman bahwa perundungan } \\
\text { tidak selaras dengan ajaran adat Minangkabau mengenai } \\
\text { urang nan sabana urang. Perundungan verbal termasuk } \\
\text { kepada sumbang kato. } \\
\text { Nilai lahia jo batin saukuran digunakan untuk menjelaskan } \\
\text { bahwa perilaku yang muncul dipengaruhi oleh pikiran dan } \\
\text { perasaan. Perubahan pikiran dilakukan dengan mempedomani } \\
\text { nilai-nilai yang terkandung dalam pepatah petitih. }\end{array}$ \\
\hline 2. Identifikasi pikiran & $\begin{array}{l}\text { Nilai raso jo pareso } \\
\text { (menyertakan perasaan dan } \\
\text { pikiran atau pemeriksaan } \\
\text { dalam bertindak). } \\
\text { Nilai iduik baraka, baukua jo } \\
\text { bajangko (Hidup } \\
\text { menggunakan akal dan } \\
\text { kemampuan mengukur dan } \\
\text { memprediksi). }\end{array}$ & $\begin{array}{l}\text { Siswa difasilitasi untuk mampu memikirkan atau memeriksa } \\
\text { keadaan diri, termasuk pikiran dan perasaan yang dimiliki saat } \\
\text { berinteraksi dengan orang lain. Kemudian menguji keakuratan } \\
\text { pikiran tersebut dan akibat pikiran tersebut menurut perasaan } \\
\text { dan logikanya (raso jo pareso). } \\
\text { Nilai iduik baraka, baukua jo bajangko menunjukkan orang } \\
\text { Minangkabau utuk selalu mengunakan dan mengoptimalkan } \\
\text { akal pikiran yang positif dalam melakukan sesuatu. }\end{array}$ \\
\hline 3. Koping pikiran & $\begin{array}{l}\text { Nilai manusia basipaik gawa, } \\
\text { Allah basipaik qadim } \\
\text { (manusia sifatnya berubah- } \\
\text { ubah, hanya Allah yang } \\
\text { kekal). } \\
\text { Nilai saiyo sakato (Saling } \\
\text { memahami dan tenggang rasa } \\
\text { antar sesama). } \\
\text { Nilai sopan santun. }\end{array}$ & $\begin{array}{l}\text { Menggunakan nilai manusia bersifat gawa atau mampu } \\
\text { berubah dalam menjelaskan cara koping pikiran. } \\
\text { Nilai saiyo sakato dan nilai sopan santun digunakan sebagai } \\
\text { pedoman siswa dalam mengganti pikiran negatif menjadi } \\
\text { positif. }\end{array}$ \\
\hline $\begin{array}{l}\text { 4. Perpindahan pikiran negatif ke } \\
\text { koping pikiran }\end{array}$ & $\begin{array}{l}\text { Nilai kehati-hatian alun } \\
\text { takilek alah takalam (mampu } \\
\text { memahami dan mengenali } \\
\text { sebelum jelas). }\end{array}$ & $\begin{array}{l}\text { Memperhatikan nilai alun takilek alah takalam untuk segera } \\
\text { melakukan koping pikiran saat siswa menyadari munculnya } \\
\text { pikiran negatif. }\end{array}$ \\
\hline $\begin{array}{l}\text { 5. Penguatan diri dengan } \\
\text { pernyataan positif }\end{array}$ & $\begin{array}{l}\text { Nilai urang sabana urang } \\
\text { (orang yang sesungguhnya } \\
\text { dalam adat Minangkabau) dan } \\
\text { nilai sopan santun. }\end{array}$ & $\begin{array}{l}\text { Nilai urang sabana urang dan sopan santun digunakan } \\
\text { sebagai acuan siswa dalam membuat pernyataan diri positif } \\
\text { sebagai penguat atau hadiah atas perubahan yang dicapai. }\end{array}$ \\
\hline 6. Tugas rumah & $\begin{array}{l}\text { Nilai belajar lanca kaji dek } \\
\text { baulang, pasa jalan dek } \\
\text { batampuah (lancar pelajaran } \\
\text { atau keterampilan karena } \\
\text { diulang). }\end{array}$ & $\begin{array}{l}\text { Nilai ini digunakan untuk mendorong siswa memiliki } \\
\text { kesadaran dalam melakukan pekerjaan rumah. }\end{array}$ \\
\hline
\end{tabular}

Tabel 4. Hasil Analisis Data Angka Penilaian Ahli dan Calon Pengguna

\begin{tabular}{lc}
\hline \multicolumn{1}{c}{ Penilai Ahli } & Indeks Validasi \\
\hline Ahli Media Pembelajaran & 0,92 \\
Ahli Konseling & 0,81 \\
Ahli Budaya Minangkabau & 0,86 \\
Calon Pengguna & 0,90 \\
\hline
\end{tabular}


Hasil penilaian ahli budaya Minangkabau memberikan angka indeks validasi sebesar 0,86. Angka ini menunjukkan tingkat validitas yang tinggi. Oleh sebab itu, panduan teknik CR bermuatan pepatah petitih untuk mereduksi perundungan verbal siswa valid dari segi nilai pepatah petitih yang digunakan. Data non angka yang diperoleh dari ahli budaya Minangkabau adalah (1) spesifikan pembagian pepatah petitih yang berhubungan dengan perundungan verbal dan teknik CR, (2) perubahan istilah nilai kesamaan menjadi nilai saiyo jo sakato, (3) penambahan nilai sumbang kato untuk mendukung nilai urang nan sabana urang, dan (4) deskripsi atau penjelasan lebih detail mengenai nilai urang nan sabana urang. Data non angka pertama dari ahli budaya Minangkabau menunjukkan perlu adanya tambahan bahasan sebagai pengetahuan calon pengguna, yaitu pemaparan pepatah petitih yang berhubungan dengan perilaku perundungan verbal. Data verbal kedua menunjukkan perlu adanya penggantian istilah dengan istilah yang lebih tepat dalam bahasa Minangkabau, penggunaan istilah nilai kesamaan diganti menjadi nilai saiyo jo sakato. Data verbal ketiga menunjukkan nilai urang sabana urang perlu didukung oleh nilai lain yang relevan, dalam hal ini digunakan nilai sumbang kato untuk mendeskripsikan perilaku perundungan tidak selaras dengan nilai-nilai budaya yang perlu diperhatikan serta contoh perilaku yang konkret.

Selanjutnya, hasil penilaian calon pengguna memberikan angka indeks validasi sebsesar 0,90. Angka ini menunjukkan tingkat validitas yang tinggi, artinya panduan teknik cognitive restructuring bermuatan pepatah petitih Minangkabau valid digunakan dan memiliki tingkat keterbacaan yang baik. Data non angka yang diperoleh dari penilaian calon pengguna adalah halaman pembatas antar Bab. Data ini menunjukkan perlu ada tambahan dan perbaikan dalam penyusunan buku panduan. Data non angka bertujuan untuk memudahkan pembaca dan memperjelas batas antar Bab.

\section{PEMBAHASAN}

Berdasarkan penilaian para ahli, panduan teknik CR bermuatan pepatah petitih untuk mereduksi perundungan verbal siswa telah memenuhi syarat kelayakan produk secara teoritis. Selanjutnya hasil penilaian calon pengguna juga menunjukkan bahwa panduan sudah memenuhi syarat keterbacaan sehingga layak dan valid untuk digunakan. Instrumen penilaiah ahli dan calon pengguna mengacu pada PP No.19/2005 pasal 43 ayat (5) tentang Standar Nasional Pendidikan yang menyebutkan bahwa buku teks pelajaran ditetapkan oleh Peraturan Mentri berdasarkan kriteria kelayakan isi, bahasa, penyajian, dan kegrafisan. Ahli media pembelajaran memberikan penilaian terhadap bahasa yang digunakan, format penyajian dan kegrafisan guku panduan, Sedangkan kelayakan isi panduan selanjutnya dinilai oleh ahli konseling dan ahli budaya Minangkabau. Item instrumen yang disusun atas aspek ketepatan, kejelasan, kegunaan dan kemenarikan.

Angka indeks validasi hasil penilaian ahli media pembelajaran menunjukkan bahwa panduan telah memenuhi syarat kelayakan sebagai media pembelajaran. Secara fisik, panduan memenuhi syarat atau ketentuan buku ajar yang terstandar dari Ristekdikti (2018). Ukuran panduan adalah B5 (17,6 cm x $25 \mathrm{~cm})$, ukuran ini mendukung kepraktisan saat digunakan oleh guru BK. Bahan sampul menggunakan artpaper glossy 270 gram yang mampu menghasilkan warna yang bagus (Renaldy, 2013).

Desain sampul mampu mendeskripsikan isi panduan secara umum, hal ini terdapat pada warna latar dan gambar yang digunakan. Sampul menggunakan kombinasi warna hitam, merah dan kuning yang merupakan warna khas adat Minangkabau. Warna khas Minangkabau ini dapat ditemukan di bendera adat yang disebut dengan marawa, bendera ini biasanya digunakan ketika acara nasional, acara keagamaan, acara daerah atau pelantikan pejabat di daerah Sumatera Barat (Navis, 1984). Desain sampul panduan juga menyertakan warna rumah gadang dan warna bendera marawa itu sendiri. Rumah gadang merupakan bangunan khas Minangkabau sebagai salah satu representasi simbolik dari identitas diri masyarakat Minangkabau (Franzia, Piliang, \& Saidi, 2015). Selanjutnya pada sampul panduan juga disertakan gambar ilustrasi perundungan verbal, yaitu menunjukkan beberapa orang anak melakukan perundungan terhadap salah seorang diantara mereka.

Halaman isi panduan menggunakan kertas HVS 70gram yang dapat menampilkan hasil cetak yang bagus dengan beberapa warna dasar. Huruf yang digunakan adalah Times New Roman ukuran 12 pt, ukuran ini bersifat proposional dengan ukuran buku yang dipilih karena memiliki skor yang tinggi pada aspek kegrafisan (As, 2009). Penyajian materi menyertakan tabel untuk menampilkan materi dengan jelas dan ringkas sehingga dapat menghindari ketidakjelasan panduan.

Angka indeks validasi hasil penilaian dua orang ahli konseling menunjukkan bahwa panduan teknik cognitive restructuring bermuatan pepatah petitih untuk mereduksi perundungan verbal siswa memenuhi syarat layak sebagai buku panduan yang memuat materi konseling. Pelaksanaan teknik cognitive restructuring dalam konseling kelompok dibagi atas enam pertemuan dan tahapan teknik dibagi pada setiap pertemuan. Durasi masing-masing pertemuan adalah 50-55 menit, durasi waktu ini telah memenuhi syarat kelayakan konseling kognitif perilaku yang setidaknya dilakukan selama 30 - 60 menit (Recipients, Cully, \& Teten, 2008).

Kegiatan konseling memperhatikan prinsip dan kegiatan konseling kognitif perilaku, dimana konseli difasilitasi untuk mampu menyadari pikiran negatif yang mendasari perilaku dan mengelolanya menjadi pikiran yang lebih positif. Oleh sebab itu, pepatah petitih yang pada dasarnya adalah kalimat atau ujaran yang berisikan nasehat kehidupan, nilai hukum dan pedoman bertingkah laku (Navis, 1984) dimasukkan dalam kegiatan berpikir dalam konseling kelompok, bukan kegiatan pemberian nasehat. Hal ini sejalan dengan model konseling kognitif perilaku yang menekankan peranan penting pikiran dalam perilaku yang ditampilkan (Corey, 2013). 
Perilaku perundungan verbal siswa diukur menggunakan instrumen berbentuk skala $1-4$. Pemilihan alat ukur ini bertujuan untuk memudahkan guru BK karena siswa dapat mengerjakannya sebagai laporan diri sesuai dengan karakteristik perilakunya (Marliani, 2018). Instrumen berbentuk skala untuk mengukur perilaku perundungan juga dilakukan oleh beberapa peneliti sebelumnya, di antaranya skala perundungan dikembangkan oleh (Cerit, Türkmen Keskin, \& Ekici, 2018; Shaw, Dooley, Cross, Zubrick, \& Waters, 2013; Strout, Vessey, DiFazio, \& Ludlow, 2018). Pengembangan panduan teknik konseling ini dilakukan dengan terlebih dahulu melakukan pengumpulan data dan informasi, analisis data dan hasilnya dijadikan dasar pengembangan panduan. Pengembangan panduan konseling kognitif perilaku yang bermuatan budaya juga didasarkan pada beberapa penelitian sebelumnya, diantaranya (Ormhaug, Jensen, Wentzel-Larsen, \& Shirk, 2014; Yates, Leung, Orgeta, Spector, \& Orrell, 2014).

Hasil penilaian Ahli budaya Minangkabau atas materi panduan yang berkaitan nilai pepatah petitih menunjukkan bahwa materi nilai pepatah petitih yang digunakan telah memenuhi syarat kelayakan sehingga valid untuk digunakan. Kelayakan materi pepatah petitih Minangkabau mendukung kelayakan isi materi konseling. Pemuatan pepatah petitih dalam teknik konseling sebagai upaya menciptakan perubahan perilaku siswa didasarkan kepada teori yang menyatakan bahwa manusia hidup dipengaruhi oleh nilai-nilai budaya dan orang sekitar (Berger, 1984).

Pepatah petitih sebagai sastra lisan yang berbentuk kiasan perlu penjelasan yang lebih detail agar nilai-nilai yang terkandung lebih mudah untuk ditangkap dan dipahami (Oktavianus, 2016; Putra, 2017). Oleh sebab itu, nilai pepatah petitih dalam panduan dijabarkan kembali dalam beberapa kalimat, disertai makna, penjelasan, dan contohnya. Penjelasan juga dikaitkan dengan perundungan verbal dan aktivitas dalam konseling. Pemuatan nilai pepatah petitih tidak hanya memperhatikan nilai perundungan verbal, namun juga makna dan tujuan kegiatan pada setiap tahapan teknik cognitive restructuring, seperti ditampilkan pada tabel. 1 .

\section{SIMPULAN}

Berdasarkan analisis hasil penilaian ahli media pembelajaran, ahli konseling serta ahli budaya Minangkabau secara keseluruhan didapatkan disimpulkan bahwa panduan teknik konseling yang dikembangkan valid dan layak digunakan oleh guru bimbingan dan konseling SMP Negeri 2 Situjuah Limo Nagari untuk mereduksi perundungan verbal siswa. Tindakan perbaikan atau revisi telah dilakukan agar panduan yang dikembangkan betul-betul dapat menjadi sebuah solusi atas permasalahan perundungan verbal dan kesulitan guru BK SMP dalam melaksanakan konseling dalam mengatasinya.

Pengambangan teknik cognitive restructuring bermuatan pepatah petitih Minangkabau yang egaliter, yaitu memandang bahwa semua manusia sama atau dikenal dengan awak samo awak. Peneliti selanjutnya dapat mengkaji terkait teknik konseling lain, seperti teknik dalam konseling perilaku. Peneliti selanjutnya juga dapat melakukan kajian teknik cognitive restructuring bermuatan pepatah petitih selain perundungan verbal.

\section{DAFTAR RUJUKAN}

Alabi, Y. L., \& Lami, M. M. (2015). Efficacy of Client-Centred and Rational-Emotive Behaviour Therapies in Reducing Bullying Behaviour among in-School Adolescents in Ilorin, Nigeria. International Journal of Instruction, 8(1), 61-74. https://doi.org/10.12973/iji.2015.815a

Ayu Suciartini, N. N., \& Unix Sumartini, N. L. P. (2019). Verbal Bullying Dalam Media Sosial. Jurnal Pendidikan Bahasa Indonesia, 6(2), 152. https://doi.org/10.30659/j.6.2.152-171

Berger, P. L. (1984). Intervention to Sociology: A Humanistic Perspective. USA: Penguin Books.

Cerit, K., Türkmen Keskin, S., \& Ekici, D. (2018). Development of Instrument of Bullying Behaviors in Nursing Education based on Structured Equation Modeling. Asian Nursing Research, 12(4), 245-250. https://doi.org/10.1016/j.anr.2018.07.002

Chrétien, M., Giroux, I., Goulet, A., Jacques, C., \& Bouchard, S. (2017). Cognitive Restructuring of Gambling-Related Thoughts: A Systematic Review. Addictive Behaviors, 75, 108-121. https://doi.org/10.1016/j.addbeh.2017.07.001

Corey, G. (2013). Theory and Practice of Counseling and Psychotherapy. Family Relations, 29(1), 133. https://doi.org/10.2307/583738

Cormier, L. S., Nurius, P., \& Osborn, C. J. (2009). Interviewing and Change Strategies for Helpers: Fundamental Skills and Cognitive Behavioral Interventions (6th ed). Australia; Belmont, CA: Brooks/Cole, Cengage Learning.

Franzia, E., Piliang, Y. A., \& Saidi, A. I. (2015). Manifestation of Minangkabau Cultural Identity through Public Engagement in Virtual Community. Procedia - Social and Behavioral Sciences, 184, 56-62. https://doi.org/10.1016/j.sbspro.2015.05.053

Hidayah, N., \& Ramli, M. (2017). Need of Cognitive-Behavior Counseling Model Based on Local Wisdom to Improve Meaning of Life of Madurese Culture Junior High School Students. Proceedings of the $3^{\text {rd }}$ International Conference on Education and Training (ICET 2017), 128. https://doi.org/10.2991/icet-17.2017.53 
Hsu, W. Y., Lin, S. S. J., Chang, S. M., Tseng, Y. H., \& Chiu, N.Y. (2015). Examining the Diagnostic Criteria for Internet Addiction: Expert Validation. Journal of the Formosan Medical Association, 114(6), 504-508. https://doi.org/10.1016/j.jfma.2014.03.010

Marliani, R. (2018). Pengukuran Dalam Penelitian Psikologi. Psympathic : Jurnal Ilmiah Psikologi, 3(1), $107-120$. https://doi.org/10.15575/psy.v3i1.2180

Munir, M. (2013). Nilai-Nilai Pendidikan Dalam Petatah Petitih Adat Minangkabau. Alhurriyah Jurnal Hukum Islam, 14(1), 10. http://dx.doi.org/10.30983/alhurriyah.v14i1.598

Narimani, M., \& Samadifard, H. (2017). The Relationship between Irrational Beliefs, Mindfulness, and Cognitive Fusion with Social Health among Elderly in Ardabil, 2016. Journal of Gerontology, 1(4), 20-28. https://doi.org/10.18869/acadpub.joge.1.4.20

Oktavianus. (2016). Nilai Budaya Dalam Ungkapan Minangkabau: Sebuah Kajian dari Perspektif Antropologi Linguistik. Linguistik Indonesia, 24(1), 1-2.

Olatunbosun, I. (2016). Efficacy of Cognitive Behaviour Therapy on Reducing Bullying Behaviour among Secondary School Students in Ikwerre Local Government Area. 4(1), 001-007, 7. https://doi.org/10.15413/ajer.2015.0125

Olweus, D. (1993). Bullying at school: What we know and what we can do. Oxford, UK ; Cambridge, USA: Blackwell.

Ormhaug, S. M., Jensen, T. K., Wentzel-Larsen, T., \& Shirk, S. R. (2014). The Therapeutic Alliance in Treatment of Traumatized Youths: Relation to Outcome in a Randomized Clinical Trial. Journal of Consulting and Clinical Psychology, 82(1), 52-64. https://doi.org/10.1037/a0033884

Putra, A. A. (2017). Nilai Adaptif-Reflektif dalam Sindir-Kias sebagai Wujud Dinamika Kebudayaan Bahasa Minangkabau. Jurnal Filsafat, 27(1), 1. https://doi.org/10.22146/jf.17240

Recipients, M. E. G., Cully, J. A., \& Teten, A. L. (2008). A Therapist's Guide to Brief Cognitive Behavioral Therapy. NW Washington DC: Department of Veterans Affairs, South Central Mental Illness Research, Education, and Clinical Center (MIRECC).

Renaldy, H. (2013). Pengendalian Kualitas Hasil Cetak Warna Berdasarkan Metoda Dmaic di PT “G” Unit Komersial. Jurnal INASEA, 14(2), 13.

Rigby, K. (2004). Reducing bullying in schools. Hindmarsh: DECS Publishing.

Shaw, T., Dooley, J. J., Cross, D., Zubrick, S. R., \& Waters, S. (2013). The Forms of Bullying Scale (FBS): Validity and Reliability Estimates for a Measure of Bullying Victimization and Perpetration in Adolescence. Psychological Assessment, 25(4), 1045-1057. https://doi.org/10.1037/a0032955

Steigerwald, F., \& Stone, D. (1999). Cognitive Restructuring and the 12-Step Program of Alcoholics Anonymous. Journal of Substance Abuse Treatment, 16(4), 321-327. https://doi.org/10.1016/S0740-5472(98)00052-X

Strout, T. D., Vessey, J. A., DiFazio, R. L., \& Ludlow, L. H. (2018). The Child Adolescent Bullying Scale (CABS): Psychometric evaluation of a new measure. Research in Nursing \& Health, 41(3), 252-264. https://doi.org/10.1002/nur.21871

Sucipto, S. (2012). Bullying dan Upaya Meminimalisasikannya. PSIKOPEDAGOGIA Jurnal Bimbingan dan Konseling, 1(1). https://doi.org/10.12928/psikopedagogia.v1i1.2566

Tumon, M. B. A. (2014). Studi Deskriptif Perilaku Bullying pada Remaja. Calyptra : Jurnal Imliah Mahasiswa Surabaya, 3(1), $1-17$.

Yates, L., Leung, P., Orgeta, V., Spector, A., \& Orrell, M. (2014). The Development of Individual Cognitive Stimulation Therapy (iCST) for Dementia. Clinical Interventions in Aging, 10, 95. https://doi.org/10.2147/CIA.S73844 